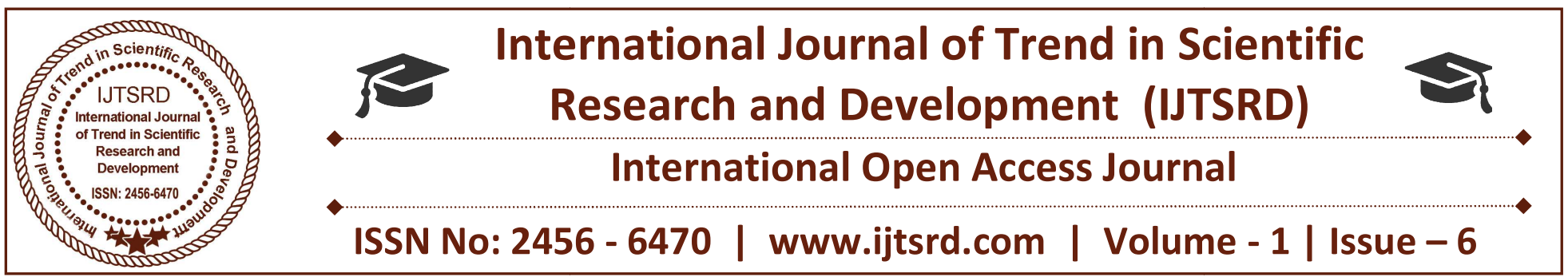

\title{
Research On an Impact of Goods and Service Tax (GST) on Indian Economy
}

\author{
G. Vijaya Bhaskar \\ PGT Economics, Telangana State Model School, \\ Nidmanoor, Nalgonda, Telangana, India
}

\begin{abstract}
GST otherwise called the Goods and Services Tax is characterised as the indirect tax structure intended to help and improve the financial development of a nation. More than 150 nations have actualised GST up until this point. Notwithstanding, the possibility of GST in India was mooted by Vajpayee government in 2000 and the amendment of Constitution of India for the same was passed by the Loksabha on sixth May 2015 however is yet to be sanctioned by the Rajyasabha. Be that as it may, there is an enormous shout against its usage. It is intriguing to comprehend why this proposed GST administration may hamper the development and improvement of the nation.
\end{abstract}

Keywords: Goods and service tax; Indian economy

\section{INTRODUCTION}

The Goods and Services Tax (GST) is a tremendous idea that streamlines the monster assess structure by supporting and upgrading the financial development of a nation. GST is an exhaustive assessment collects on assembling, deal and utilisation of merchandise and enterprises at a national level [1]. The Goods and Services Tax Bill or GST Bill, additionally alluded to as The Constitution (One Hundred and TwentySecond Amendment) Bill, 2014, starts a Value included Tax to be actualised a national level in India. GST will be a circuitous duty at all the phases of creation to realise consistency in the framework. On bringing GST into training, there would be amalgamation of Central and State charges into a solitary expense instalment. It would likewise improve the position of India in both, residential and additionally global market. At the customer level,
GST would diminish the general taxation rate, which is right now assessed at 25-30\%. Under this framework, the customer pays the last assessment however a productive info impose credit framework guarantees that there is no falling of charges assess on assess paid on inputs that go into fabricate of merchandise [2]. With a specific end goal to maintain a strategic distance from the instalment of various charges, for example, extract obligation and administration impose at Central level and VAT at the State level, GST would bind together these assessments and make a uniform market all through the nation. Mix of different assessments into a GST framework will realize a successful cross-usage of credits. The present framework charges generation, while the GST will mean to assess utilisation.

Specialists have enrolled the advantages of GST as under:

It would present two-layered One-Country-OneTax administration.

It would subsume all roundabout duties at the middle and the state level.

$>$ It would not just extend the assessment administration by covering merchandise and ventures yet in addition make it straightforward.

It would free the assembling area from falling impact of assessments, hence by enhance the costaggressiveness of products and enterprises.

It would cut down the costs of merchandise and enterprises and hence by, increment utilisation.

It would make business-accommodating condition, along these lines by increment charge GDP proportion. 


\section{Why no to GST?}

Be that as it may, the inquiry is: is the photo as blushing as it is depicted? Money Street firm Goldman Sachs, in a note 'India: Q and An on GST Growth Impact Could Be Muted', has put out assessments that demonstrate that the Modi Government's model for the Goods and Services Tax (GST) won't raise development, will push up customer costs expansion and may not bring about expanded expense income accumulations [3]. There gives off an impression of being sure escape clauses in the proposed GST impose administration which might be inconvenient in conveying the coveted outcomes. They are: India has embraced double GST rather than national GST. It has made the whole structure of GST genuinely convoluted in India. The inside should facilitate with 29 states and 7 union regions to execute such assessment administration. Such administration is probably going to make financial and additionally political issues. The states are probably going to lose the say in deciding rates once GST is actualized. The sharing of incomes between the states and the middle is as yet a matter of conflict with no agreement arrived in regards to income impartial rate. Boss Economic Advisor Arvind Subramanian on 4 December 2015 recommended GST rates of $12 \%$ for concessional products, $17-18 \%$ for standard merchandise and $40 \%$ for extravagance merchandise which is substantially higher than the present most extreme administration charge rate of $14 \%$. Such activity is probably going to push swelling.

\section{Need for GST:}

India's current advance towards monetary development originates from changes attempted after the 1991 financial emergency, which lifted India from many years of moderate development under communist manage and offered a chance to enhance living conditions in the colossal, poor nation. In the meantime much had changed in India after adjust of instalments emergency of 1991. Indian arrangements turned out to be more positive about advancing fare and enabling outside funding to take an interest during the time spent India's growth1. Globalization and progression have moved toward becoming request of the day. The relationship of economies in their turn for improvement constrained the Governments of the considerable number of nations to take after the globalization approaches embraced by the significant economies of the world. To survive and develop in this financial request objective and focused assessment strategies are being received by each nation. India has additionally fallen in accordance with the prerequisite and has been starting adjustments in immediate and roundabout assessments. The current recommendations of Direct Taxes Code (DTC) and Goods and Services Tax (GST) are considered as way softening up the monetary rebuilding when all is said in done and in the tax assessment range specifically.

Process and Framework of GST: To actualize complete circuitous expense change in the nation the then Union Finance Minister Mr. P. Chidambaram while displaying Union Budget for the year 2007-08 reported such that GST would be presented from 01/04/2010 and an Empowered Committee of State Finance Ministers was constituted. The Finance Minister said that the Committee would work with the Central Government to set up a guide for presentation of GST in India. After this declaration the Empowered Committee of State Finance Ministers chose to setup a joint working gathering on May 10, 2007. The Joint working gathering after serious inner talk and communication with specialists and delegates of Chambers of Commerce and Industry presented its answer to the Empowered Committee in Nov. 2007. After-words a spate of considerations and dialogs were held from among various intrigue bunches including exchange and industry bodies in the last seven-eight years.

\section{Importance of GST:}

Directly, the Constitution engages the Central Government to demand extract obligation on assembling and administration assess on the supply of administrations. Further, it enables the State Governments to demand deals expense or esteem included assessment (VAT) on the offer of products. This select division of financial forces has prompted a variety of aberrant assessments in the nation. What's more, focal deals charge (CST) is exacted on between State offers of products by the Central Government, yet gathered and held by the trading States. Further, many States exact a section impose on the passage of products in neighborhoods.

a) This variety of duties at the State and Central levels has brought about a complex circuitous expense structure in the nation that is ridden with concealed expenses for the exchange and industry. Right off the 
bat, there is no consistency of expense rates and structure crosswise over States. Also, there is falling of assessments because of 'charge on impose'. No credit of extract obligation and administration impose paid at the phase of make is accessible to the brokers while paying the State level deals duty or VAT, and the other way around. Further, no credit of State charges paid in one State can be benefited in different States. Henceforth, the costs of products and ventures get falsely expanded to the degree of this 'duty on charge'.

b) The presentation of GST would stamp a reasonable takeoff from the plan of dissemination of financial forces imagined in the Constitution. The proposed double GST imagines tax collection of the same assessable occasion, i.e., supply of products and enterprises, all the while by both the Center and the States. Along these lines, both Center and States will be engaged to require GST over the esteem chain from the phase of make to utilization. The credit of GST paid on contributions at each phase of significant worth expansion would be accessible for the release of GST obligation on the yield, along these lines guaranteeing GST is charged

\section{The proposed GST regime appears to be unfavorable for telecommunication sector as well}

"One of the major drawbacks of the GST regime could be the direct spike in the service tax rate from $14 \%$ to $20-22 \%$ " (GST: Impact on the Telecommunications Sector in India). The proposed GST appears to be silent on whether telecommunication can be considered under the category of goods or services. The entire issue of telecommunication sector assumes a serious proportion when India's rural teledensity is not even $50 \%[5]$.

\section{The proposed GST regime intends to keep petroleum products, electricity, real estate and liquor for human consumption out of the purview of GST}

It is a well-known fact that petroleum products have been a major contributor to inflation in India. Inflation in India depends on how the government intends to include petroleum products under GST in future. Electricity is essential for the growth and development of India. If electricity is included under standard or luxury goods in future then it would badly affect the development of India. It is said that GST would impact negatively on the real estate market. It would add up to $8 \%$ to the cost of new homes and reduce demand by about $12 \%$.

VII. The proposed GST regime "would be capable of being levied on sale of newspapers and advertisements therein"

This would give the governments the access to substantial incremental revenues since this industry has historically been tax free in its entirety" [6]. It sounds ridiculous but the provision of GST is likely to make the supervision of operations by its Board/senior managers across the company's offices in different parts of the country a taxable service by allowing each state to raise a GST demand on the company. Again there appears to be lack of consensus over fixing the revenue rate as well as threshold limit. One thing is for sure, services in India are going to be steeply costly if GST is fixed above the present service tax rate of $14 \%$ which in turn will spiral up inflation in India. "Asian countries which implemented GST all had witnessed retail inflation in the year of implementation [6,7].

\section{Conclusion}

The proposed GST administration is an indifferent endeavor to defend backhanded expense structure. More than 150 nations have executed GST. The administration of India should examine the GST administration set up by different nations and furthermore their aftermaths previously executing it. In the meantime, the legislature should make an endeavor to protect the immense poor populace of India against the reasonable swelling because of execution of GST. Almost certainly, GST will streamline existing circuitous expense framework and will evacuate wasteful aspects made by the current heterogeneous tax collection framework just if there is an unmistakable accord over issues of edge restrain, income rate, and consideration of oil based commodities, power, alcohol and land. Until the point that the agreement is achieved, the legislature should oppose from actualizing such administration.

\section{REFERENCES}

1) The Economic Times (2009) Featured Articles from The Economic Times.

2) Gst India (2015) Economy and Policy. 
3) Mehra P (2015) Modi govt.'s model for GST may not result in significant growth push. The Hindu.

4) Sardana M (2005) Evolution Of E-Commerce In India Part 3.

5) TRAI (2015) Highlights of Telecom Subscription Data as on 28th February.

6) Patrick M (2015) Goods and Service Tax: Push for Growth. Centre for Public Policy Research (CPPR).

7) SKP (2014) GST: Impact on the Telecommunications Sector in India. 